\section{THE MOVEMENTS OF THE EARTH ${ }^{1}$}

\section{I. - Measurement of Space}

IN proceeding to deal with the application of the various branches of physical science to the investigation of those phenomena which lie beyond the earth, there is a very large field from which to make choice of a subject which will show, now the application of one branch of science, and now the application of another, and bring us, in this way, somewhat nearer to the truths and the beauties wbich lie in the most distant realms of space for all who will take the trouble to look for them. But perhaps it may be more desirable to select that part of the subject which, so to speak, lies nearer home, and endeavour to point out how, by means of the application of principles, and methods, and instruments which are generally familiar, and which at all events are of daily use, the various movements with which our planet is endowed may be studied, not only with reference to the phenomena themselves, but with reference also to the causes which lie at the bottom of them.

The various branches of knowledge which will have to be drawn upon in furni: hing the materials necessary for this inquiry were really started long before it was imagined that the earth had any movements at all; but still, on the whole, the growth of the knowledge of its movements has been so beautifully continuous, that we cannot do better now than consider historically the way in which those sciences have grown up, which enable us to make certain measurements, and to get out correctly certain quantities, which must necessarily lie at the bottom of any sound knowledge.

What particular things do we want to measure? It has been already said that when the sciences to which attention will have to be called later on were founded, very few people on this planet knew that it moved at all, but it is now generally known that the earth does move. It will be obvious however that, whether the earth moves or not (and that may be considered still a moot question), if we wish to form a basis for our judgment in any direction, we must be able to measure time and space. It has been well said that "time and space are the moulds in which phenomena are cast;" for when it is desired to gain any useful knowledge concerning any fact, the relation which it bears to the things around it, and the time of its occurrence must be known, and that is the only thing an astronomer tries to do when he is investigating that portion of his subject to which we must first turn our attention. We will begin then by considering those measurements of space which are of the first importance to the astronomer. I do not here refer to the ordinary familiar measurement of inches, yards, and miles, but to the measurement of angles, and it will be well to get a good no!ion of this angular measurement as soon as possible.

There is no special necessity for dividing the circle into 360 parts, but the greatest number of people have made that division, and it is still continued to be done. When the Chinese began to make circles they divided them, not into 360 parts, but into $365 \frac{1}{4}$. Now there was a great advantage, and a great disadvantage about that. The advantage was that this number of divisions in the Chinese circle was the same as the number of days in the year; the disadvantage was that they were not dealing with whole numbers, and their $365 \frac{1}{3}$ was not such a convenient number to halve and quarter, and so on, as is 360 . In quite recent times it has been suggested that 400 parts should be taken instead of 360 , but that is a suggestion which up to the present time has not been acted upon.

We have then an angle defined as the inclination of two straight lines starting from a centre; if we get one of these lines traversing an entire circumference, the other remaining at rest, the travelling line will have traversed $360^{\circ}$; we have what is called a right angle when one of the lines has been separated from the other through a quarter of a circumference-that is, $90^{\circ}$. This is the fundamental idea of angular measurement, the only measurement of space with which we shall have to deal at present.

For instance, if a little ivory rule be opened, its two parts become inclined to each other, and inclose what is known as an angle. That angle may be made large or small by opening and closing the two parts, $\mathbf{A}$ and $\mathbf{B}$ (see Fig. I) of the rule. Suppose the rule to be shut, the point on which it turns being in the centre of the circle, CDEF, and that, whilst $A$ remains at rest, $B$ is made to travel successively

${ }^{1}$ Report of Lectures to Working Men given at the Royal School of Mines by J. Norman Lockyer, F.R.S. through $B$ and $B^{1}$ to $B^{2}$. It will then have travelled half the circumference of the circle CDEF, but civilised people, in order to get perfectly clear notions about this measurement, and to be able to tell each other what particular measurement they have made in this way, instead of talhing of a circumference merely,

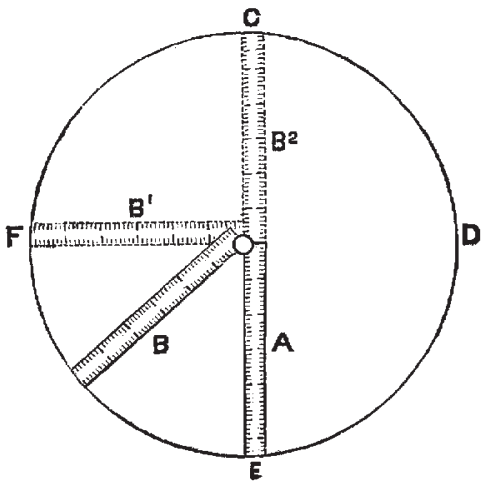

FIG. r. -Use of a two-foot rule to explain angular measurement. With the part $A$ at rest, the movement of the other to $B, B^{I}$ and $B^{2}$ gives us $45^{\circ}$, $90^{\circ}$, and $r 80^{\circ}$.

and of certain rough divisions of it, have divided all circles into 360 parts called degrees, and say that the travelling part, $\mathrm{B}$, of the rule has travelled through not a quarter, or a half circumference, but through 90 and 180 degrees respectively.

Why are these measurements of space required? For the reascn that when we are dealing with the heavenly bodies and seeking to define the position of any object, two facts at least are required to be known before its exact position can be determined. An observer going out at night upon an extended plain would see some celestial bodies near where the earth meets the sky all round, which is called the circle of the horizon, and he might happen to see another body exactly overhead, in what is called the zenith. In passing from this zenith to the horizon it will be obvious that a quarter of a circumference is traversed (see Fig. 2). That distance may therefore be divided into $90^{\circ}$.

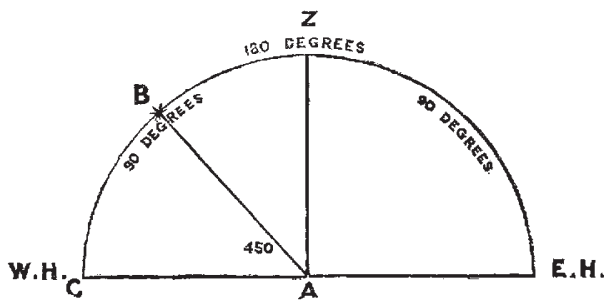

FIG. 2.-Measurement of altitudes.

Similarly in passing from the eastern horizon to the western horizon half a circumference is travelled over. This distance therefore is divided into $180^{\circ}$ of angular measurement in the same way that the half of the circumference traversed by the travelling rule was divided into $180^{\circ}$.

Now if it can be ascertained of any body that it is exactly in the zenith, the position of that one body has been definitely stated for the particular time at which the observation is made. But consider the case of another body not in the zenith. Suppose that the lines, the one A B (see Fig. 2), passing from the observer to the object, and the other, AC, passing from the observer to the horizon, inclose an angle of $45^{\circ}$. This angle is called the star's altitude. But to say simply that the altitude of a star is $45^{\circ}$ does not sufficiently define its position. Let the reader imagine himself to be standing in the Albert Hall. He knows that he may look up and see rows of panes of glass and ornamented work running around the hall at different heights above the floor. He may also notice, let us say, various series of ornamentation arranged vertically from floor to rocf. Now suppose it were desired to define the position of any one pane of glass or piece of ornamentation in any one of these horizontal or vertical rows. It is obvious that to say of any pane of glass at one level that it is at a certain height above the floor will not suffice, for all the panes of glass in that row are at the same 
elevation. In like manner in defining the position of any one piece of ornamentation in the vertical series it will not be suffcient to say that it is at a certain angular distance from any one point, say a door, because all the pieces in the same row are at this angular distance from the door. But if these two methods of stating position be combined, if the height above the ground as well as the angular distance from the door be given, then a definite statement may be made both of the position of the pane of glass and the piece of ornamentation. Similarly with the stars. Imagine a horizontal circle passing from north to south, and thence to north again. A line from the zenith through any body will cut this circle at some one point, and the number of degrees included between that point and the north point will give the angular distance from the north point, or, as it is calied, the azimutb. The whole of an imaginary line of bodies extending from the zenith to the horizon will have the same azimuth (see Fig. 3). In the same way we may imagine a whole ring of bodies

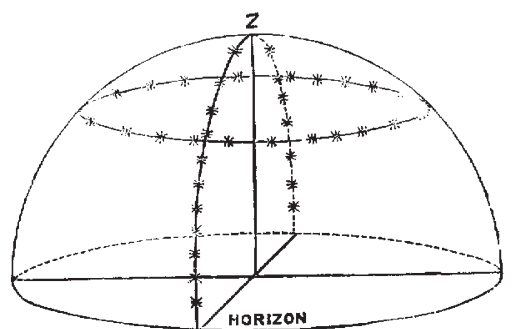

FIG. 3.-Stars with equal altitudes and stars with equal azimuths.

at the same height above the horizon, having the same altitude (see Fig. 3), but a particular altitude and a particular azimuth can be true of only one of those bodies. It is in this way, then, by a statement of the altitude and azimuth, that the position of a star or other celestial body can be indicated with reference to any one particular place of observation and any one particular instant of time.

It is by thus dealing with this angular measurement that the exact positions of the heavenly bodies have been determined.

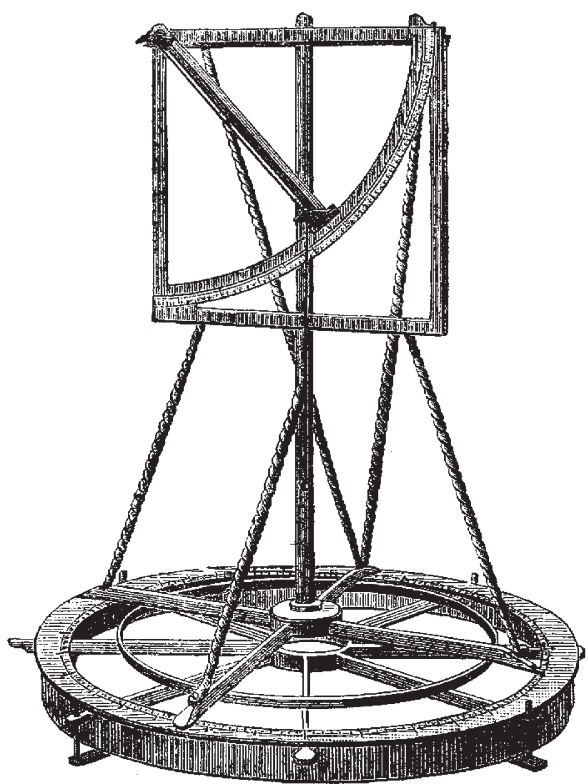

FIG. 4.-Tycho Brahe's altitude and azimuth instrument.

This point has been discussed at some length, because in making an historical survey it will be found, that the growth of that particular knowledge of which we shall come to speak, has been the growth of man's capability of getting finer and finer in this angular measurement. To go back to the time of the old Greeks, Hipparchus, one of the most eminent of ancient observers, even in his day could define the position of a heavenly body to within one-third of a degree. Since these 360 degrees into which circles are divided are each subdivided, first into 60 minutes, and each of these again into 60 seconds, the one third of a degree to which Hipparchus attained may be called 20 minutes of arc.

Passing from his time to the middle ages, a most interesting instrument then in use claims attention. Fig. 4 is a copy of a photograph of the instrument.

The model, from which the photograph has been taken, is an exact copy of an instrument made by one of the most industrious astronomers that ever lived, Tycho Brahe, and shows how, even in the very beginning of this observational science, men got at a very admirable way of making their observations, considering the means they had at their disposal. First there was in this instrument a quadrant of a circle (see Fig. 4), which served their purpose just as well as a whole circle. Combined with this was an arrangement somewhat resembling the "sights" on a modern rifle. Remember this was before the days of telescopes. So they started with these sights and a little pinhole, that they might take a shot, as it were, at a heavenly body, putting the eye near the pinhole, and seeing the heavenly body in a line with the front sight. Then the instrument was provided with a plumbline to show the vertical. This plumbline was so arranged that when the sight lay along it, a body in the zenith would be observed, and an angle of $90^{\circ}$ altitude recorded. With the instrument thus set, any smaller altitude could be read along the quadrant, according to the position of the line of sight passing through the eye, the centre of the quadrant, and the place of the heavenly body.

To get azimuth they used a horizontal circle, shown at the base, also divided into degrees and provided with a pointer. By sweeping the instrument round until the azimuth was such that the body was seen through the pinhole, and the altitude was such that it was seen in a line with the front sight, they fixed its position, as well as that instrument enabled it to be done. Supposing that their circles were properly divided, it was quite easy to determine a division as small as the quarter of a degree. This would put Tycho Brahe in only a little better position than Hipparchus. That is to say, from the time of the Greeks until about the middle of the fifteenth century, the only advance made with this angular measurement, was that a reading of one-third was improved into a reading of one-fourth of a degree.

Another notable improvement and advance towards a finer and more accurate measurement was made by Digges. $\mathrm{He}$ introduced the diagonal scale, the principle of which is shown in Fig. 5. The arrangement consists of a number of concentric

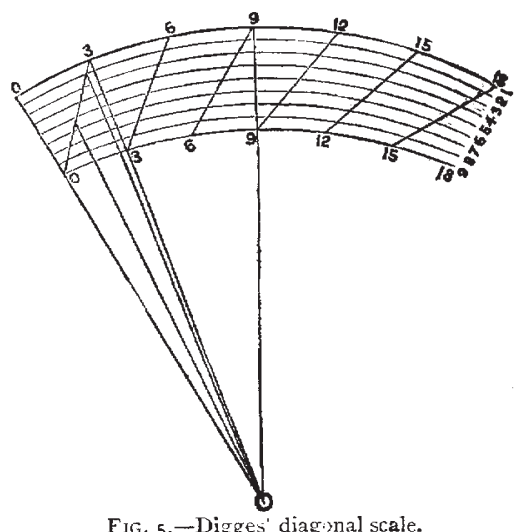

circles, in this case nine. The distance between the divisions of the inner circle is $3^{\circ}$. From each of these divisions diagonal lines are drawn to the outer circle in such a manner that the diagonal cutting the first circle at $0^{\circ}$ cuts the ninth circle at $3^{\circ}$. That cutting the first circle at $3^{\circ}$ cuts the outer circle at $6^{\circ}$. So with the other diagonal lines. Consider the diagonal passing from $0^{\circ}$ on the inner circle to $3^{\circ}$ on the outer. If the pointer cuts the scale at the former point, an observation of $0^{\circ}$ will have been made ; if it cuts at the Iatter point, an observation of $3^{\circ}$ will have been made. But it may cut the scale at some intermediate point. Suppose it falls on the eighth of the nine concentric circles, then the value of the observation will be $7 / 8$ ths of $3^{\circ}$. Should the pointer fall half way between $0^{\circ}$ and $3^{\circ}$, the reading 
will be $4 / 8$ ths of $3^{\circ}$. So with the other intermediate points. In this way, then, Digges enabled a much greater accuracy to be at tained in this circle reading.

The next great improvement after that of Digges was one made by M. Vernier, a Frenchman, who, in about the year $163 \mathrm{r}$, in. vented the instrument which bears his name. The following is the arrangement. Let the scale on which the measurements are made be divided into a certain number of parts. Take a second

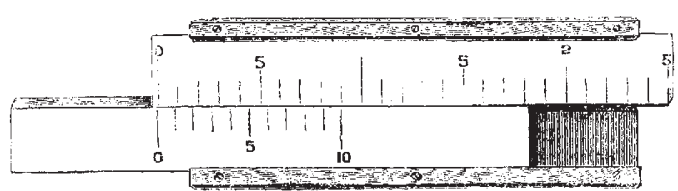

F1G. 6.-Vernier reading to tenths of divisions.

scale called the vernier, shorter than the first by the length of one of its divisions, and make the number of divisions in this vernier equal to the number of divisions in the scale. Then each of the divisions of the vernier, will be less than each of the parts of the scale, by a fraction having one for its numerator, and the number of divisions in the scale or vernier respectively for its denominator. Thus if the number of divisions be ten (see Fig. 6), and the vernier equal in length to nine of such

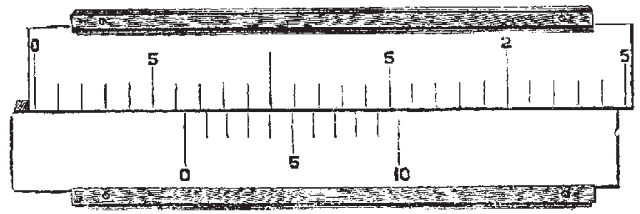

Fig. 7.-Vernier shown in Fig. 6 reading to three-tenths.

parts has also ten divisions, each of these divisions will be shorter by $1 /$ roth than each of the parts of the scale. If the number of divisions be seventeen (see Fig. 8) the different parts, of the vernier will be less by $1 / 17$ th than each of the divisions of the scale. So when the number of divisions is thirty (see Fig. 9), the parts of the vernier will be less by I/3oth than the divisions of the scale. The arrangement, however, is not limited to straight scales. It may also be used for the determination of small

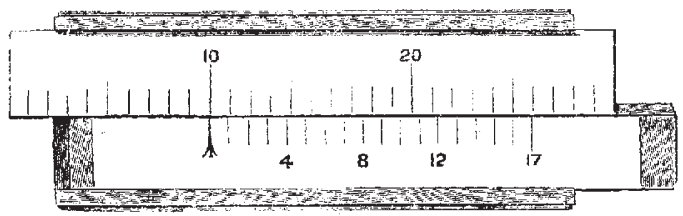

Frg. 8.-Vernier reading to seventeenths.

fractions of degrees on a circle. Fig. Io represents a vernier giving tenths of degrees on a circle. It need hardly be said that the vernier may be construcied to give readings upon the inner as well as the outer edge of the graduation.

In using the vernier the observer looks along it until he meets a coincidence, that is for a point where one of the divisions on the scale coincides with a division on the vernier. If this occurs at the eighth division, then the observation is some whole num-

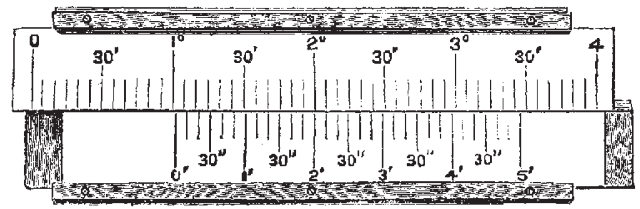

FIG. 9. A pplication of vernier to circle reading to one-tenth of a degree.

ber, and $8 / 1$ oths, $8 / 17$ ths, or $8 / 3$ oths, according as the scale used is divided into ten, seventeen, or thirty parts. In Fig. 7 the coincidence occurs at the third division; the reading in that case would be some whole number and 3 / Ioths.

To the instrument of Tycho Brahe, then, the vernier, which can beadapted to it, has now been added. Of course by taking divisions enough the measurement may be made as fine as pos. sible. A vernier of 100 divisions may replace the vernier of Io, of I7, or of 30 divisions. Seventeen divisions have been chosen to show that the principle is not limited to tenths. Any number of divisions may be taken. A very fine degree of accuracy can be attained then in angular measurement, owing to the introduction of the vernier, and that is why there is what is practically a vernier upon almost every measuring instrument in every workshop and laboratory. The question next arises whether with the introduction of the vernier the limit of accuracy has been reached, or whether it be possible to go beyond this. A negative reply may be made to this question. The

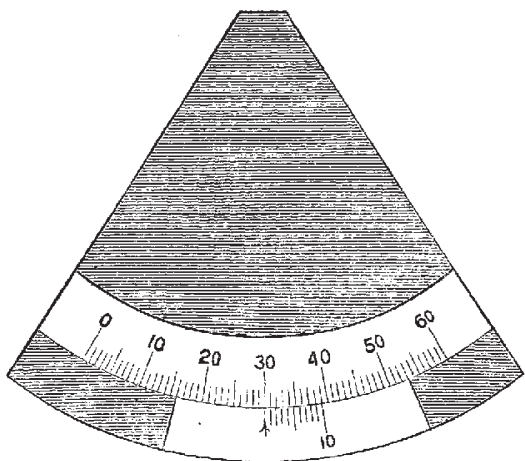

FIG. 10.-Application of vernier to circle reading to ten seconds of arc.

limit of accuracy has not here been reached. In order to get more accuracy in this angular measurement, it is only necessary to add some branch of physical science to those geometrical considerations by means of which circles have been so finely divided. The astronomer culls certain portions out of the science of optics, and uses them for his purpose. It is perfectly clear that the reason a limit is reached with an arrangement of the nature of the vernier is; that at last the divisions get so small that the eye cannot distinguish them, so that optical principles have to be appealed to to increase the power of the eye.

Before discussing this question of whether it be possible to

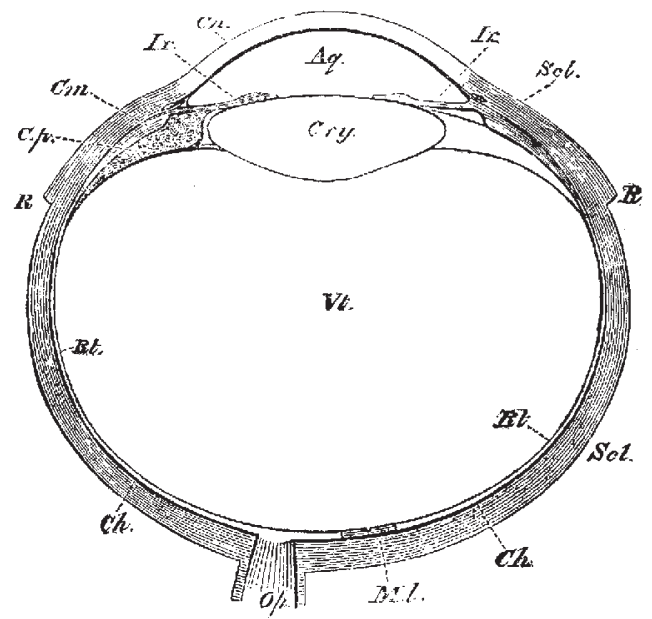

Fig. II.-Horizontal section of the human eye.

select some principle of optics, by the application of which the power of the eye may be increased, it will be well to con. sider in what it is that that power consists. Fig. II will give a rough notion of those parts of the eye which specially relate to this matter. First comes the curved surface $C n$, the cornea, and next $A q$, the small anterior chamber which contains the aqueous humour. Behind this comes Ir, the iris, which limits the amount of light entering the eye, this being immediately succeeded by $C r y$, the crystalline lens. Then comes the large posterior chamber of the eye which contains the vitreous humour. Behind this the optic nerve enters the eyeball, ex- 
panding itself into the delicate layer of nervous elements, $R t$, which lines the inner surface of the vitreous cavity.

When any object is seen by the eye, the rays of light emanating from that body, impinging first upon the curved corneal surface, have to pass successively through $A q, C r y$, and $V t$, betore they can affect the nervous retinal elements and cause the sensation of light. In passing through these portions of the eye, the rays of light are dealt with in a peculiar manner, eipecially perhaps by the crystalline lens, and are brought together to form what is called an image on the retina. This image infuences the nervous elements of which the retina is composed in such a way, that a sort of telegram is sent to the brain through the optic nerve, and the brain becomes conscious of having seen something, the par. ticular object seen being included in the message. Another diagram (Fig. I2) will perhaps make it a little clearer how this image on the retina is formed. At $A B$ is an arrow ; from it rays of light are marked going to the three different points on the retina. But it will be seen that those rays of light which come from the top of the arrow are, by the action of these three media, twisted downwards, and form an image of the top portion of the arrow on a low part of the retina. The rays of light proceeding from the bottom of the arrow are bent up, so that its image is formed on an upper part of the retina. The light coming from the middle of the arrow is not bent at all, and therefore forms its image on a middle portion of the retina. That is the way in which the eye deals with rays of light entering

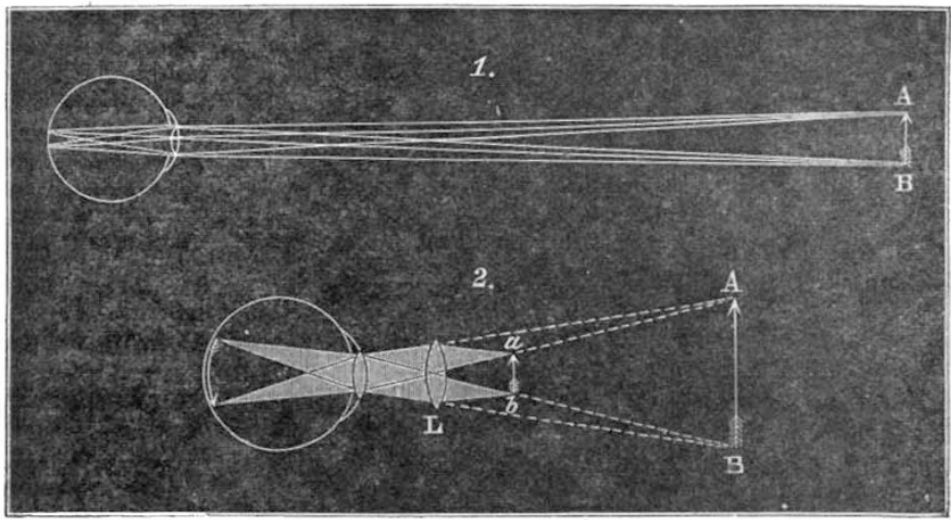

FIG. I2.-x. Diagram showing path of rays when viewing an object at an easy distance. 2. Object brought close to eye when the lens'L is required to assist the eye-lens to observe the image when the object is magnified.

it. With this knowledge of the optics of the eye, it will be very easily seen how very wo.derfully the construction of the eye has been imitated in a photographic camera. The front lens is practically the equivalent of those three refractive media of the eye, the aqueous and vitreous humsurs, and the crystalline lens; whilst the iris, which in the eye serves to limit the amount of light entering it, has its exact representative in the "stop," which serves the same end in the camera. The photographic plate is, it need hardly be said, the counterpart of the retina, and has consequently been beautifully described as "a retina which does not forget." Similarly there is just such an arrangement for focusing the light as exists in the eye. In fact a cam ra is a rather better machine altogether than the eye, because the range is greater, and the focusing power is not lost as age increases. Therefore the artificial eyes of our camera are never in need of spectacles.

I. How Optics enables us to Read Fine Verniers. -This know. ledge, then, having been acquired, how is it to be utilised for the purpose of the measurement of angular space? It may be utilised in this way. The reason that we cannot clearly distinguish objects placed very close to the eye is, that the rays of light which flow from them are so extremely divergent that the crystalline lens cannot focus them on the retina. But by placing between the eye and the object a double convex lens, that is a lens like the cryitalline lens of the eye, this extreme divergence is corrected; the crystalline lens is thus aided, and the rays of light are brought to a focus, as shown in the lower part of Fig. 12. Take the case of a vernier whose divisions are so fine that they are not visible at the distance of distinct vision, say about ten inches. If we attempt to correct this by making the divisions appear larger, by bringing the vernier close to the eye, we lose the power of focusing the rays which flow from it. But the introduction of a convex lens between the vernier and the eye enables the eye to see the division quite distinctly.

Of course the more nearly an object approaches the eye, the more powerful must be the lens, in order that the eye may clearly see it. In this way we see that the simple addition of a convex lens has enormously increased our power of observing and measuring small angles,

2. One can, however, go further than this, and use not one simple lens, but a combination of lenses. But before discussing the various combinations of lenses which are employed in various instruments, it is necessary to look a little more closely than we have yet done at the structure and action of our convex lens. Let us use a glass lens in conjunction with an electric lamp. Then we may get an image of the carbon poles thrown on the

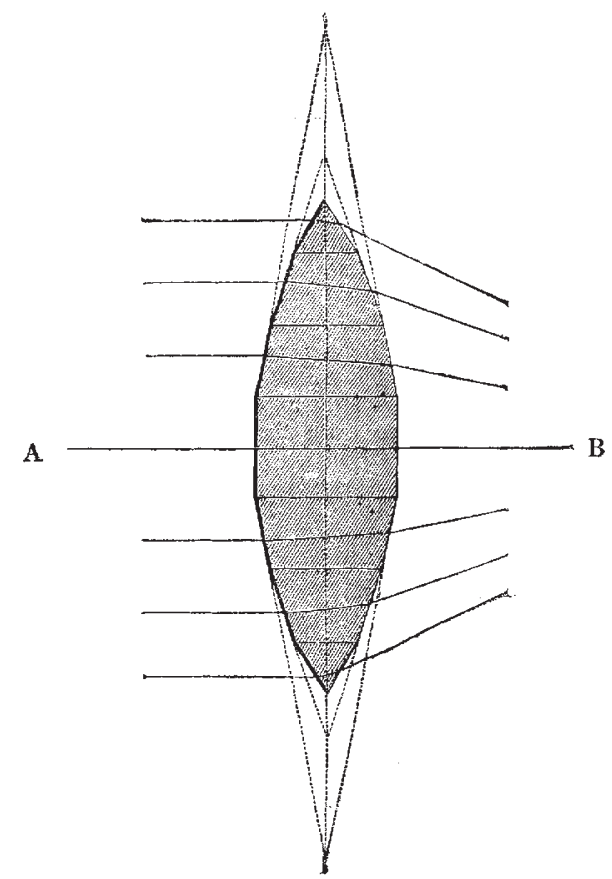

FIG. I3.-Formation of a lens from sections of prisms.

screen, in exactly the same way that the crystalline lens forms its image on the retina. But there would be this important difference, that while the image formed by the crystalline lens would 
be a clear and distinct one, that formed by our glass lens would be a very bad one : instead of the poles of the electric arc being clearly and sharply defined, they would appear as if seen in a haze, and would be surrounded by coloured fringes of light, and not much could be made of them. Why is this? We find by experiment that this attempt to imitate the action of the eye by means of such a simple glass lens is an incorrect way of proceeding, the eye possessing certain qualities which the simple glass lens does not. Although a lens seems to be a very simple matter, its structure is really based upon some very complicated considerations. If a section of it be taken it will be seen that its surface is built up of sections of triangular pieces of glass, these triangular pieces of glass being called prisms, and how they deal with the light it is very important for us to know. If in front of the beam of light issuing from the lantern a prism be interposed, it will be found that whilst part of the light is re-

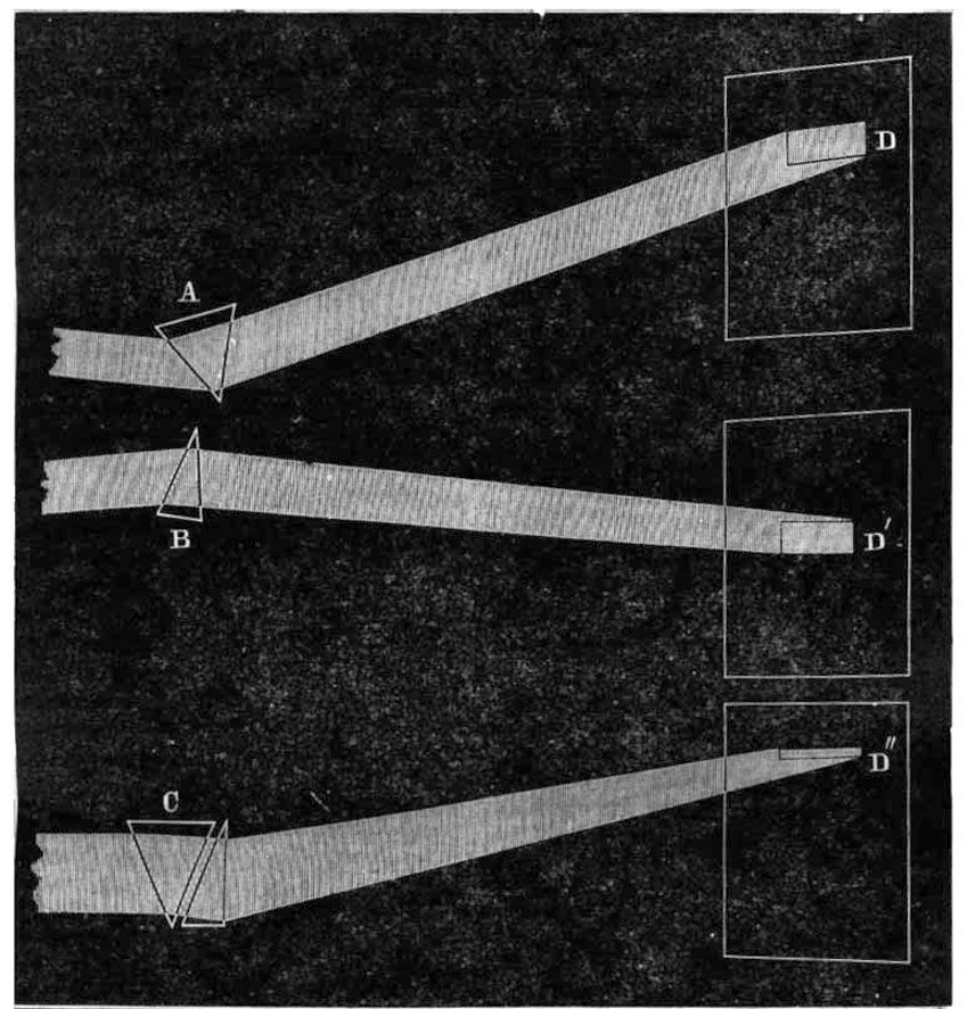

FIG. 14.-Diagram explaining the formation of an achromatic lens. A, crown-glass prism; B, flint-gl iss prism of less angle, but" giving the sameramount of colour; $C$, the two prisms combined, giving a colourless yet deviated band of light at $\mathrm{D}^{\prime \prime}$.

flected from its first surface another portion is refracted as it surrounded by a false glow, because it is difficult to give the lens is termed, that is, bent out of its original course by the prism. the proper curvature, and there is this power of dispersion which Further, it not only suffers this deviation due to refraction, but it breaks the compound white light up into a number of its different undergoes also what is called dispersion. In fact, where the elementary colours. It is this power of deviation which the lens light falls on the screen an infinite number of different colours possesses which enables it to bend the rays differently according are seen, these forming what is called a spectrum. This is one of to their different distances from its centre, and causes them to the reasons why such a glass lens as we have used will not per. form an image at what is termed the focus of the lens. The form the finer work of the eye; the images of the po'es are rays of light passing through the outer part of the lens undergo

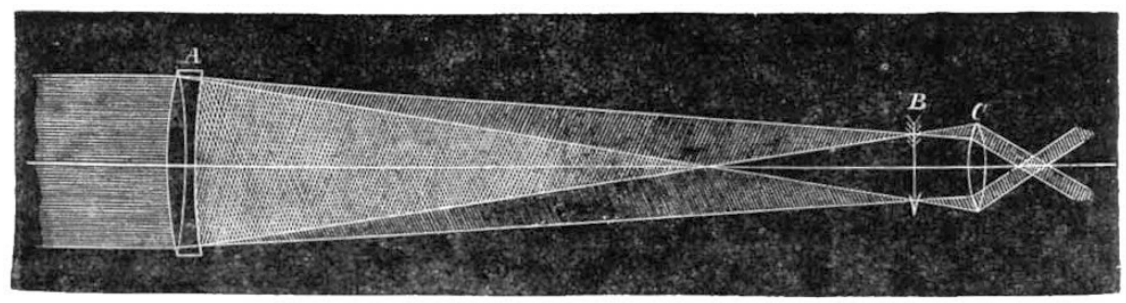

FIG. I5.-Telescope. A, object-glass, giving an image at B; c, lens for magnifying image B.

more deviation in order that they may be brought to a focus at the same point as the other rays. Now prisms which are made of different material, although they ibe of the same size and of the same angle, produce idifferent deviations and different dispersions of the light which falls upon them. This fact has been taken advantage of in the construction of lense: Let us take an illustration of the way in which this has been done. Imagine glass which gives a high dis- persion and but slight deviation, set to work against glass giving great deviation with but little dispersion. It is obvious that it is quite possible by a combination of that character to keep the deviation and get rid of the dispersion, or. to keep the dispersion and get rid of the deviation, as may be desired. By doing this an artificial eye of great excellence may be made. Suppose two different kinds of glass so combined as to form a prism, which should give a perfectly white image. Then the 
dispersion will have been got rid of, and the deviation will have been retained, and this is exactly what takes place in the modern compound, or, as it is called, achromatic lens. By building up a lens in this way we can get a much better image of the carbon poles of the lamp than before. This compound, achromatic lens, when used in a combination, is called the object-glass, because it is pointed to the object. But when it is a question of the combination of lenses, there is something else to be con. sidered besides the mere formation of images. It is not enough to consider merely this, because when we spoke of the action of a convex lens in aiding us to read the vernier, we found that if an image was to be obtained the rays entering the eye must be practically parallel. In that case the rays always come to a focus at the same point. If the rays are not parallel, but divergent rays, then their focus will vary with the varying distance of the source of light.

In combining lenses together, then, it is important to bear in mind the fact that the rays of light which, after passing through the lenses ultimately reach the eye, must be parallel ones. Let us consider that arrangement which obtains in the telescope. In the simple form of this instrument, A (Fig. I 3), representing the objectglass, receives the rays of light and forms an image of the distant arrow, from which they are supposed to flow, in exactly the same way that the lens we used just now formed an image of the carbon poles on the screen.

This image, then, having been observed, the eye views the distant object as if the object itself were placed at $\mathrm{B}$. Remember now the way in which the eye was enabled to read the vernier placed close to it, and the action of the convex eyepiece of the telescope will be very obvious. In just the same way as the divergent rays coming from the vernier were grasped by the convex lens, and rendered parallel, so in this case the convex eyepiece of the telescope grasps the divergent rays from the image, reduces them

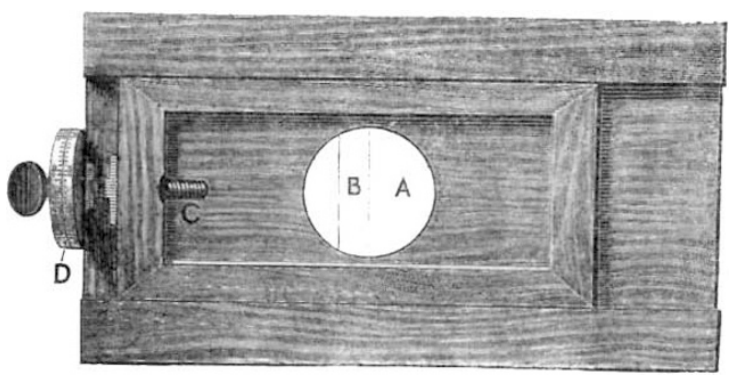

FIG. r6.-Model of Micrometer.

to the necessary condition of parallelism, and thus enables the image of the object to be clearly formed upon the retina of the observer's eye.

We have, then, got so far that by means of an object-glass we produce an aërial image, and by means of a convex lens we can view this image under conditions which enable another image of it to be formed on the retina. It is at once obvious that we can do something more than this, for if we place a concrete thing such as a cross wire at the same distance in front of the convex lens as the aërial image, or, in other words, at the focal distance of the object.glass, we shall see both the aerial image and the concrete thing, be it a cross wire or what not, both together. Now imagine that we can obtain an aërial image in this way of a star, and that side by side with this image of the star we observe the cross wire. It is quite clear that if we have any means of getting the cross wire to bisect the image of the star we shall have a much more accurate method of pointing at the celestial body; and therefore of measuring the angle between two celestial bodies, than was possible on the old system of sights without telescopes.

Suppose this telescope of ours to supplant the pointer of the old instrument of Tycho Brahe, consider the extreme accuracy of its observation as compared with that of the pointer in Tycho's quadrant, and it will be seen how vastly the application of these optical principles has added to the instrumental powers of the astronomer.

3. How Optics enables us to Replace the Vernier by a Micrometer. - But we have not yet done with optics. Its principles have been applied in yet another manner, but still, like these two applications which we have considered, tending to increase the power of accurately measuring minute angular distances of space.

Fig. I4 shows a simple model which has been designed to illustrate the principle of the instrument called the micrometer. This instrument places in the hands of the astronomer the power of measuring with extreme accuracy the most minute distances. It consists of two vertical wires, one, A, fixed, the other, B, movable by the rotation of a very perfectly cut screw, seen at $C$. The head of the screw, $\mathrm{D}$, is divided into 100 parts, and read by means of a vernier to $1 /$ roooths.

This system of threads moving over certain small distances which can be accurately measured by means of a micrometer screw, can replace the cross wires to which we have just referred, and there are two very notable applications of this principle to which reference must now be made. When the object-glass is used for astronomical purposes, it is naturally arranged to bring the rays which fall upon it from a celestial body, and which are practically parallel, to a focus which represents the actual focus of the lens for such rays, and which is called the principal focus. But it is not necessary that the rays which fall upon such a lens should be parallel. The lens acts under other conditions with this proviso, that the more the rays diverge from the body in front of it, or, in other words, the nearer the object is to it, the greater will be the distance behind the lens of the point at which the aërial image is formed.

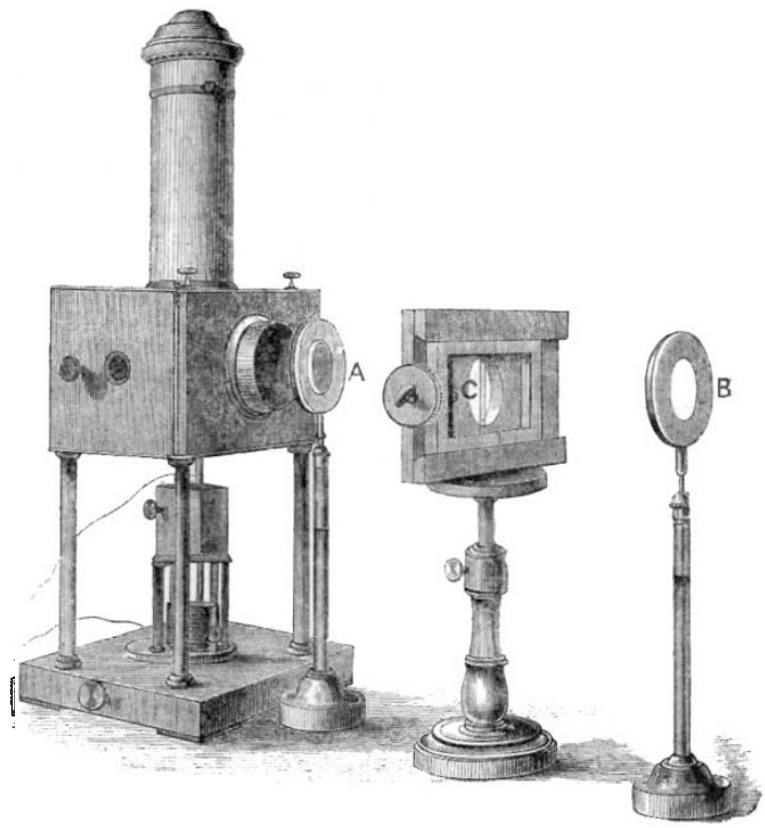

FIG. 17,-Micrometer arranged for demonstration with the electric light.

Here in a few words we have a statement of the arrangement used in the microscope, and a moment's thought will show that such an arrangement may te applied to the verrier instead of the small lens, to which reference has already been made. Nay, we can go further than this, it may be applied to the circle itself, and help us to measure small fractional divisions of its parts with yet greater accuracy than is possible by the aid of the vernier. The way in which this is managed is as follows:-The microscope is turned towards the circle, so that its divisions may be plainly seen in the field of view, and the position of the wire, on, or bet $x$ een any division may represent a certain position which is to be measured by means of the circle. The micrometer head may now be used to tell us the exact distance in $I /$ roooths of a revolution between the position occupied by the wite in the first instance, and the position of the wire when it exactly lies on the rext division. By determining, according to the graduation of the circle, the number of thousandths of parts as indicated by the micrometer which lie between each division, it is obvicus that the exact angular distance between such a position and the next division of the circle can be accurately determined. Such an operation as this is called a "run," and practically such a 
system as this is adopted in reading all large circles. But when it is a question of measuring smaller arcs, the micrometer may be used with the telescope itself, its wires appearing with the image of the object in the field of view.

A description of an experiment will perhaps convey a better idea of what can be done in this way. Fig. 15 represents the arrangement. The condensing lens of the lantern having been removed, the light is allowed to impinge upon a lens, A, placed at a slight distance from the lantern. Its action on the light causes a reversed image of the poles to be produced in the air. The light coming from this image is then made to pass through another lens, B ; the reversal is corrected, and a magnified image of the poles of the electric are is thrown upon the screen. The first lens which forms the image may be regarded as the objectgliss of a telescope, whilst the other lens which throws the mag. nified image upon the screen is the counterpart of the telescope's eyepiece. Now if at $\mathrm{C}$, where the image is formed in air, the micrometer wires are placed, they, with the image of the poles, will appear magnified on the screen.

In this manner bodies appear with the wires in the field of vision of the telescope, and their diameters and the dimensions of different parts of them may be most accurately determined. $\mathrm{Up}$ to the present time we have been concerned simply with accurately determining the positions occupied by the various bodies which people space. But with this micrometer in the field of view of the telescope something more than this may be done. We may now determine some measurements upon the bodies whose positions alone we have been considering up to now. For instance, the image of a rlanet may be grasped by the wires, one wire bounding one limb of the planet, the other wire lying along the other limb. Then, knowing how many complete turns, and $I /$ looth, and $I / I$ cooth parts of a turn have been given to the head of a screw in order that the wires may be separated through such a distance, and knowing also the value of these divisions in seconds of arc, the diameter of the planet may be measured. In like manner, the heights of lunar mountains may be ascertained by measuring the lengths of the shadows thrown by them. Or it may be a question of the distance between two stars close together. The method is still the same. One star is made to lie along the movable wire, the other is seen on the fixed one, and the distance through which the wires are separated ascertained. Having attained to this, let us bring our inquiry into angular measurement to a close.

In passing, as we shall in the sequel, from the measurement of space to the measurement of time, it will be found that the difficulties have been grappled with very much in the same way. In this measurement of space we began with simple instruments, and only by a slow grow th has the modern instrument been arrived at; yet notwithstanding the immense changes that have taken place, the pointer and circle of the old instrument are still represented in the new, whilst the vernier and micrometer, still preeminent, enable a degree of fineness to be attained quite unparalleled in the old days. But in passing from these older instruments, in which the circle was so prominent a feature, and the pointer so small, to the more modern instruments, it will be seen that, although both are still preserved, a great change has taken place. The pointer, represented by the telescope, is the prominent part of the instrument, whilst the circle is hidden away almost out of sight.

J. NORMAN LOCKYER

(To be continued.)

TABLE OF DIFFERENT VELOCITIES EXPRESSED IN METRES PER SECOND

THE following table has heen drawn up by Mr. James Jackson, Librarian to the Paris Geographical Society :-

\begin{tabular}{clllllr} 
A man walking 4 kilometres an hour & $\ldots$ & $\ldots$ & $\ldots$ & $\ldots$ & I.II \\
\hline,, &.. & $\ldots$ & $\ldots$ & $\ldots$ & I 40
\end{tabular} Metres per
second.

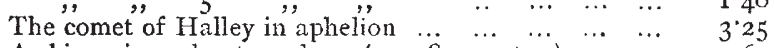
A ship going 9 knots an hour $(9 \times 1852$ metres $) \ldots \ldots \ldots$

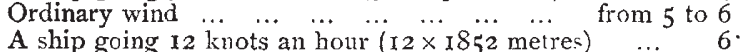
A ship going 12 knots an hour (12 21852 metres)
A wave 30 metres in magnitude with a depth of 300 $\begin{array}{cccccccccc}\text { metres } \ldots & \ldots & \ldots & \ldots & \ldots & \ldots & \ldots & \ldots & \ldots & \ldots\end{array}$ A ship going 17 knots an hour $(17 \times 1852$ metres $) \cdots$

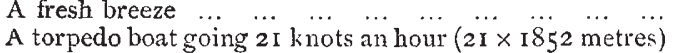

\section{$6 \cdot 8 \mathrm{I}$} $8 \cdot 75$ Io 10.80
A race-horse trotting an English mile in 2 min. $14 \mathrm{sec} . \begin{gathered}\text { Metres per } \\ \text { second. }\end{gathered}$ ,, ,, galloping 900 metres a minute $\quad \ldots \quad$.. $\quad$ I5 An express train running 60 kilometres an hour $\ldots . . . \quad 16.67$ $\begin{array}{llllll}\text { Flight of a falcon, of a carrier pigeon } & \ldots & \ldots & \ldots & \ldots & 18\end{array}$

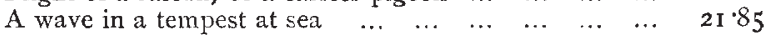
An express train ruming 60 English miles an hour $\begin{array}{lllllllll}(60 \times 1609 \text { metres }) & \ldots & \ldots & \ldots & \ldots & \ldots & \ldots & \ldots & 26.8\end{array}$ $\begin{array}{llllllllll}\text { A tempest } & \ldots & \ldots & \ldots & \ldots & \ldots & \ldots & \ldots & \ldots & \text { from } 25 \text { to } 30\end{array}$

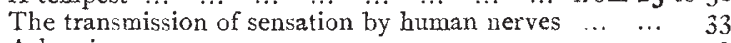
$\begin{array}{lllllllllll}\text { A hurricane } & \ldots & \ldots & \ldots & \ldots & \ldots & \ldots & \ldots & \ldots & \ldots & 40\end{array}$ $\begin{array}{llllllll}\text { Flight of one of the swiftest birds } & \ldots & \ldots & \ldots & \ldots & \ldots & \ldots & 40 \\ & \ldots & \ldots & \ldots & \ldots & \end{array}$ $\begin{array}{lllll}\text { Velocity of a point on the equator of Mercury } & \ldots & \ldots & 146.87\end{array}$ Propagation of the tide caused by the earthquake of Arica on August 13, 1868 (Arica to Honolulu), according to Hochstetter...

$\begin{array}{lllllll}\text { Velocity of a point on the equator of Mars } & \ldots & \ldots & \ldots & 227.38\end{array}$ $\begin{array}{lllll} & & \\ & \end{array}$

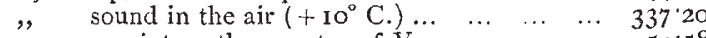
$\begin{array}{lllll}, & \text { a point on the equator of Venus ... } & \ldots & \ldots & 454.58\end{array}$

$\begin{array}{lllllllllll} & , & & & & & & \text { the Earth } & \ldots & \ldots & 463 \\ \text { A cannon ball } & \ldots & \ldots & \ldots & \ldots & \ldots & \ldots & \ldots & \ldots & \ldots & 500\end{array}$

Propagation of the movement of tides (North Pacific

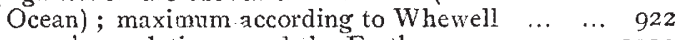

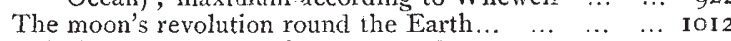
$\begin{array}{lllll}\text { Velocity of a point on the equator of Mercury } & \ldots & \ldots & 1034\end{array}$ $\begin{array}{lllll}\text { Revolution of the second satellite of Mars } \ldots & \ldots & \ldots & \text { 1 } & 57\end{array}$ Concussion of the earthquake of Viège (July $25, \quad 1855$ ); from Turin to Geneva in 126 seconds $\ldots \ldots \ldots$ $\begin{array}{llllll}\text { Velocity of sound in water }\left(+8^{\circ} \cdot \text { I C. }\right) \ldots & \ldots & \ldots & \ldots & \mathbf{1} 435\end{array}$ $\begin{array}{llllll}\text { Revolution of the first satellite of Mars ... } & \ldots & \ldots & \ldots & \ldots & 1833\end{array}$ Velocity of a point on the equator of the Sun $\ldots$. 2028 Revolution of the fourth satellite of Uranus ...

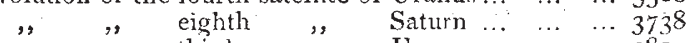

Velocity of ", third ", Uranus ...

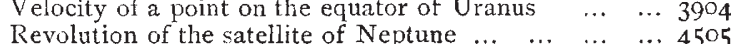
$\begin{array}{lllllll}, \quad & , \quad & \text { second satellite of Uranus... } & \ldots & \ldots & 4906\end{array}$

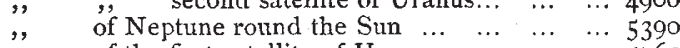
", of the first satellite of Uranus $\quad \ldots \quad \ldots \quad \ldots \quad 5763$

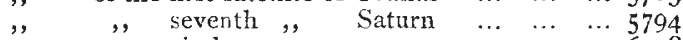

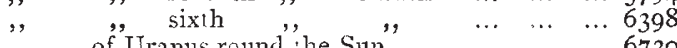

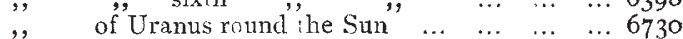

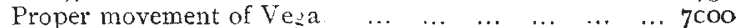

Displacement of the sun towards the constellation of Hercules

Revolution of the fourth satellite of Jupiter …

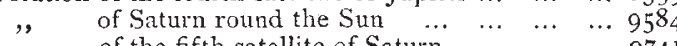
$\begin{array}{llllll}, & \text { of the fifth satellite of Saturn } & \ldots & \ldots & \ldots & 9584 \\ & \ldots & \ldots & 974 \mathrm{I}\end{array}$

Velocity of a point on the equator of Saturn... $\quad \ldots \quad$ I0,54 Revolution of the third satellite of Jupiter $\ldots . \quad \ldots \quad$ I0,869

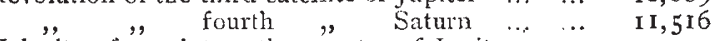

Velocity of "a point on the equator of Jupiter $\ldots . \quad \mathbf{I} 2,49 \mathbf{I}$ $\begin{array}{lllll}\text { Revolution of Jupiter round the Sun } & \ldots & \ldots & \ldots & \mathbf{1 2}, 924\end{array}$ $\begin{array}{lllll},, \quad \text { of the third satellite of Saturn } & \ldots & \ldots & \mathbf{1 2}, 924 \\ & 13,038\end{array}$

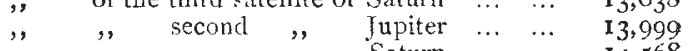

, " $\quad$ " $\quad$," $\quad$ Saturn $\quad \ldots \quad \ldots \quad 14,568$

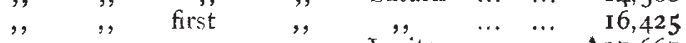

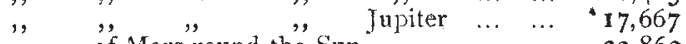

$\begin{array}{lllllll}, & \text { of Mars round the Sun } \ldots & \ldots & \ldots & \ldots & 23,863 \\ \text { of the Earth }, & , & \ldots & \ldots & \ldots & 29,516\end{array}$

$\begin{array}{lllllll}", \quad \text { of Venus } & , & , & \ldots & \ldots & \ldots & 29,516 \\ , " & \ldots & \ldots & \ldots & 34,630\end{array}$

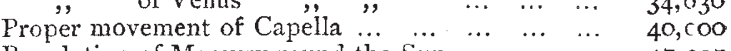
$\begin{array}{llllll}\text { Revolution of Mercury round the Sun } & \ldots & \ldots & \ldots & \ldots & 47,227\end{array}$ $\begin{array}{lllllll}\text { Proper movement of Sirius } & \ldots & \ldots & \ldots & \ldots & \ldots & 5 \mathbf{I}, 000 \\ \text { Ordinary movements of the solar } & \text { atmosphere } & \end{array}$

from 30,000 to 65,000

Proper movement of the $6 \mathrm{Ist}$ of Cygnus $\quad \ldots \quad \ldots \quad$ 7I,600

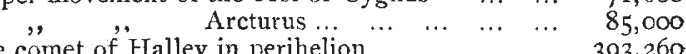
$\begin{array}{llllll}\text { The comet of Halley in perihelion } \ldots & \ldots & \ldots & \ldots & 393,260\end{array}$

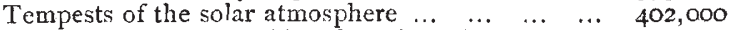
Electricity; a telegraphic submarine wire $\ldots . \quad \ldots 4,000,000$ Velocity of light " aërial $\quad, \quad \ldots \quad$ 36,000,000 $\begin{array}{llllllll}\text { Velocity of light } & \ldots & \ldots & \ldots & \ldots & \ldots & \ldots & 300,400, \text { cOO }\end{array}$

\section{THE BRITISH ASSOCIATION REPORTS}

Report of the Committee on Electric Standards, read by $\mathrm{Mr}$. R. "i. Glazebrook. - This comprised an account of the means 